\title{
Dos hábitos às instituições: proposições analíticas e metodológicas na Economia Institucional de Thostein Veblen
}

\author{
Chaiane Leal Agne \\ Universidade Estadual do Rio Grande do Sul \\ Octavio Augusto Camargo Conceição \\ Universidade Federal do Rio Grande do Sul
}

\section{Resumo}

O uso da noção de instituição ficou cada vez mais recorrente nos últimos anos, especialmente nos estudos nas áreas da economia e do desenvolvimento. Apesar disso, são limitadas as pesquisas que trazem as contribuições da Original Institutional Economics e de Thorstein Veblen, particularmente sobre a natureza evolucionária das instituições. Nesse âmbito, tais investigações carecem da compreensão sobre os seus caminhos analíticometodológicos, que são fundamentados na interdisciplinaridade. Assim, o presente artigo tem como principal objetivo discutir sobre os pressupostos teórico-analíticos da economia institucional Vebleniana e apresentar algumas possibilidades metodológicas para as pesquisas que objetivam entender as mudanças institucionais. Os principais conceitos que a literatura contemporânea produziu, centrados principalmente nas várias contribuições de Geoffrey Hodgson, gravitam em torno dos conceitos de reconstitutive downward causation ou effects e de cumulatividade, que, de maneira interativa com os indivíduos produzem um novo nexo micro-macro, ou na relação agente-estrutura. $O$ entendimento de que as instituições operam em multiníveis, cujas mudanças são facilitadas pelas interações sociais em redes, pode ser um caminho para explicar as transformações em regras, especialmente na realidade da agricultura familiar e produção artesanal de alimentos. No entanto, a construção de uma nova ontologia sobre as mudanças institucionais no tema do desenvolvimento está em fase inicial. Esse processo, que pode ser configurado como uma proposta de resgate e atualização da análise institucional Vebleniana, exige dos pesquisadores a realização de recortes analíticos: sustentados pela combinação de técnicas qualitativas e quantitativas, na busca de captar a heterogeneidade e a dinâmica dos hábitos coletivos.

Palavras-chave: Instituições. Evolucionismo. Economia Institucional. Desenvolvimento Econômico. 


\title{
From habits to institutions: analytical and methodological propositions in the Thostein Veblen Institutional Economy
}

\begin{abstract}
In the last years, the notion "institution" has been increased in the economic and development researches. However, there is little research on Original Institutional Economics (OIE), particularly the evolutionary aspect of institution from Thorstein Veblen. Therefore, there is lack of understanding from theoretical and analytical aspects, which is based on interdisciplinary elements. Accordingly, this article aims to discuss Thorstein Veblen's institutional economy and to present analytical and methodological ideas on changes of institutions. The main concepts from Original Institutional Economics literature's are centred on Geoffrey Hodgson contributions, particularly the notion as "reconstitutive downward causation or effects", where individuals interact and produce new habits from agency-structure. The understanding that institutions operate in multilevel, whose changes are facilitated by social networks, might be help to explain the changes of rules, especially in the reality of family agriculture and food processed. However, this ontology proposal is on the initial stage. This process - which can be configured as a proposal for the updating Veblenian institutional analysis, requires researchers to carry out analytical cuts: combinating qualitative and quantitative techniques, in order to capture the heterogeneity and dynamics of collective habits.
\end{abstract}

Keywords: Institutions. Changes. Institutional Economics. Economic Development.

\section{De los hábitos a las instituiciones: proposiciones analíticas y metodológicas en la Economía Institucional de Thostein Veblen}

\section{Resumen}

El uso de nociones de institución se quedó cada vez más recurrente en los últimos años, especialmente en los estudios en los áreas de la economía y del desarrollo. A pesar de eso son limitadas las investigaciones que traen las contribuciones de la Original Institutional Economics y de Thorstein Veblen, particularmente sobre la naturaleza evolutiva de las instituciones. En este ámbito, dichas investigaciones necesitan de comprensión acerca de sus caminos analítico-metodológicos que son fundamentales en la interdisciplinariedad. Así el objetivo del presente artículo tiene como principal objetivo discutir acerca de los presupuestos teórico-analíticos de la economía institucional Vebleniana y presentar algunas posibilidades metodológicas para las investigaciones que objetivan entender las mudanzas institucionales. Los principales conceptos que la literatura contemporánea produjo, centrados principalmente en varias contribuciones de Geoffrey Hodgson, gravitan alrededor de los conceptos de reconstitutive downward causation or effects y del acumulativo, que, de manera interactiva con los individuos producen un nuevo nexo micromacro, o en la relación agente-estructura. El entendimiento de que las instituciones operan en multinivel, cuyas mudanzas son facilitadas por las interacciones sociales en red, puede ser un camino para explicar las transformaciones en reglas, especialmente en la realidad de la agricultura familiar y producción artesanal de alimentos. Sin embargo, la construcción de una nueva ontología acerca de las mudanzas institucionales en el tema del desarrollo está en la fase inicial. En ese proceso, que puede ser configurado como una propuesta de rescate y actualización en la análisis institucional Vebleniana exige de los investigadores la realización de recortes analíticos: sustentados por la combinación de técnicas cualitativas y cuantitativas, en la búsqueda de captar la heterogeneidad y la dinámica de los hábitos colectivos.

Palabras clave: Instituciones. Mudanzas. Economía Institucional. Desarrollo Económico. 


\section{INTRODUÇÃO}

O uso da noção de instituição ficou cada vez mais recorrente nos últimos anos, especialmente nos estudos nas áreas da economia e do desenvolvimento. $\mathrm{Na}$ maioria das pesquisas, a instituição tornou-se um elemento explicativo do sucesso e/ou do atraso de regiões e/ou de localidades. Caso um determinado município, organização ou empresa não atingisse resultados econômicos favoráveis ao "desenvolvimento", uma das principais razões apontadas pelos "institucionalistas" consistia na carência de uma estrutura de governança ou de instituições "eficientes". Tal viés tornou-se usual na literatura devido à disseminação dos pressupostos e receituários metodológicos da Nova Economia Institucional - NEI de Ronald Coase, Oliver Williamson e Douglass North. Não discordamos dessa afirmativa, mas consideramos que ela é insuficiente, embora relevante, para tratar de questões analíticas tão complexas. O receituário conceitual e metodológico da $\mathrm{NEI}$, mesmo trazendo novidades, não inclui elementos capazes de explicar as diferenças nos resultados de desenvolvimento econômico, que diferem segundo as características sociais e culturais das regiões. A nosso ver, tais idiossincrasias são muito menos questões de regras e de custos de transação do que de formações de hábitos culturais e de comportamentos sociais. Por essa razão, consideramos importante excursionarmos brevemente sobre as recentes explorações do legado da Original Institutional Economics - OIE sobre tão complexo tema, que tem, principalmente, nos escritos de Veblen, mas também de Commons e Mitchell, seus principais expoentes.

Grande parte dos ensinamentos de Thorstein Bunde Veblen permaneceu à margem da discussão sobre instituições, principalmente entre os anos de 1940 até meados dos anos 1960 (Hodgson, 1998). Tal omissão se dava à equivocada suposição de que o incompreendido legado da OIE devia-se à falta de teoria, que deixou para a história ou para o esquecimento, um conjunto de ideias, sem teoria e sem um nexo digno de ser considerado como tal. Na realidade, todo o legado da OIE, e de Veblen, devia-se à incompreensão de "o que seria uma economia evolucionária", fato esse só devidamente esclarecido a partir dos anos de 1980, principalmente com a relevante contribuição de Nelson e Winter, An Evolutionary Theory of Economic Change. A partir daí, noções como mudança tecnológica e institucional passaram a ser (re)incorporadas ao debate econômico e uma (re)leitura vebleniano começou a tomar forma.

A noção de instituição - até então percebida como sinônimo e certeza de "eficiência" - especialmente pelos escritos da NEI - tornou-se insuficiente para explicar as formas heterogêneas de desenvolvimento dos países e das regiões. Começou-se a (re)entendê-la como agente de mudança e reorientação "estrutural" de toda a economia, oriunda dos padrões de comportamento e de conduta - leia-se "hábitos" - dos indivíduos que habitavam esse ambiente econômico. De fato, as instituições passaram a ser consideradas como a "causa" do desenvolvimento, mas não por aquelas razões, mas por essas. É disso que nos ocuparemos no presente texto. 
Para tanto, o presente artigo tem como principal objetivo avançar nas discussões em torno da economia institucional vebleniana, relacionando-a com os seus pressupostos teórico-analíticos e, ainda, apresentando algumas possibilidades metodológicas para as pesquisas na área do desenvolvimento. É importante ressaltar que a noção de desenvolvimento à qual estamos nos referindo diz respeito às condições de crescimento econômico comprometidas com os avanços sociais, dos pontos de vistas histórico, qualitativo e evolucionário. Ademais, o desenvolvimento - assim como as instituições - é múltiplo, pois adquire diferentes contornos e nuances que estão relacionados aos distintos ambientes sociais e culturais.

O presente texto está subdivido em cinco seções, incluindo a introdução e as considerações finais. Na segunda seção, será discutido sobre a diversidade institucional, ideia implícita na noção de instituições de Thorstein Veblen. A heterogeneidade dos hábitos de pensamento e de comportamento nos permite afirmar que há a necessidade dos pesquisadores "institucionalistas" realizarem um recorte analítico, capaz de tornar a abordagem operacional, ao mesmo tempo em que forneça subsídios para sintetizar resultados. Na terceira seção, serão apresentados os principais conceitos e nexos teóricos, oriundos de uma nova ontologia evolucionária vebleniana, que vincula a relação indivíduo-instituição por meio de uma análise interativa-cumulativa.

$\mathrm{Na}$ quarta seção, serão discutidas as limitações do coletivismo e do individualismo metodológico, que reduzem a forma de compreensão do comportamento humano. Veblen, na busca de entender o comportamento humano, propõe a análise sobre os hábitos, que são, por sua vez, as formas como os indivíduos percebem a sociedade e agem coletivamente. O ponto de partida é um nexo interacional, ou seja, do indivíduo para a instituição e vice-versa. Apesar de o presente artigo fornecer algumas pistas para operacionalização dessa perspectiva, não há um único caminho de instrumentalização, já que ele se modifica de acordo com o objetivo, particularidade e contexto empírico da pesquisa. Ainda na quarta seção, serão apresentadas algumas ideias de combinação entre a Velha Economia Institucional e outras noções interdisciplinares, discutindo também propostas de métodos para pesquisa na temática das instituições. $\mathrm{O}$ artigo finaliza com as considerações finais.

\section{NÃO HÁ UMA ÚNICA “INSTITUIÇÃO": A HETEROGENEIDADE INSTITUCIONAL VEBLENIANA}

No capítulo 8 do livro "A teoria da classe Ociosa", publicado em 1899, Veblen, ao analisar os estilos de vida das classes ociosas no contexto americano no final do século XIX, define instituições. O autor usa tal contexto para sustentar a tese de que tais costumes são legitimados e reproduzidos pelos hábitos dos indivíduos e dos grupos sociais, que se manifestam em pensamentos e nos comportamentos. Embora seu interesse estivesse relacionado aos modos e costumes de consumo da sociedade da época, a noção de instituições é atualizada, e pode constituir ainda uma definição bastante útil para entender inúmeras problemáticas sociais da atualidade. 
No pensamento de Veblen, a economia está permeada por um conjunto de fatores em processo de evolução, sendo que os hábitos dos indivíduos formam a base para o processo de seleção e formação de novas instituições (VEBLEN, 1987). As instituições são, portanto, resultantes do processo de interação humana, podendo tanto restringir quanto reproduzir o comportamento dos indivíduos. Essa premissa da análise interacional indivíduo-instituição é ainda a principal característica que difere essa perspectiva dos ensinamentos da NEI.

As instituições, segundo Veblen, não adquirem consistência somente em papéis (como contratos e acordos formalizados) e/ou estruturas físicas (organizações, entidades públicas e privadas). Pelo contrário, elas dependem das interpretações e das condutas que os indivíduos têm sobre elas, que podem convergir ou não com as estruturas formais. As atitudes humanas, formadoras dos hábitos mentais e de vida são ainda passíveis de questionamentos, crises, conflitos e consensos. Assim, os contratos, acordos, normas e regras formais podem ou não ser "institucionalizados", na medida em que podem ser legitimados socialmente ou não. Como menciona Veblen (1987, p.32), “uma norma determinada permanece em vigor somente quando tem o apoio do hábito ou aptidão que constitui o critério de seu desenvolvimento, ou pelo menos não é incompatível com ele".

Uma das principais características da noção de instituição vebleniana é o elemento evolucionário que traduz a forma e dinâmica com que os hábitos humanos são transformados, preservando aspectos do passado e incorporando “novos" atributos do presente. Essa transformação - processual e evolucionária - é dependente da história e da forma como os indivíduos a interpretam e agem coletivamente, formando "novas" necessidades, preferências e objetivos. Dessa maneira, instituições representam o modo como as pessoas interpretam, experimentam, tomam decisões e agem em sociedade. Essa definição indica a heterogeneidade dos hábitos, o que limita, por exemplo, o alcance das políticas públicas e das legislações no que diz respeito à construção de padrões de comportamento e de mudança social.

Apesar da pluralidade institucional não estar explícita nos argumentos de Veblen (1987), tal característica fica evidente quando relacionada às problemáticas na área do desenvolvimento. Um dos exemplos refere-se ao papel do Estado na formulação de programas e políticas públicas para a sociedade. Quando determinados agentes se reúnem, discutem e formulam políticas e programas sociais, a ideia que está implícita é a tradução de hábitos coletivos, na medida em que eles representam as interpretações que os agentes envolvidos têm sobre os problemas e as possíveis "soluções" para o público-alvo. Dependendo do grupo social analisado, tal programa ou política traduzem as suas necessidades e/ou interesses, enquanto que, em outros, essas mesmas "instituições" podem ser totalmente ou parcialmente inadequadas às suas demandas. Nesse exemplo, o aspecto evolucionário e a característica "blind drift" das instituições estão presentes, já que os resultados eficientes são colocados em xeque: os agentes não possuem informações completas, logo, eles estão limitados em traduzir as necessidades humanas. As instituições são, portanto, passíveis de erros e acertos. 
As instituições são resultantes de interpretações coletivas do passado, assim como os novos hábitos são constituintes dos ideais coletivos, daquilo que projetamos para o futuro. Na atualidade, com a velocidade das informações, com a crescente diversidade de demandas sociais e as consequentes transformações na vida humana, é provável que tenhamos uma heterogeneidade cada vez maior de instituições, de diferentes níveis e características. Se considerarmos apenas a gama de opções de leis, programas e políticas brasileiras podemos observar a diversidade dos hábitos envolvidos, que vão desde os formuladores até os "operacionalizadores" e os públicosalvos. O "enraizamento" das instituições com a sua realidade social permite afirmar ainda que não é possível desenvolvê-las de maneira programada, seguindo um receituário ou tampouco transferindo-as de um contexto social para outro. Esse enraizamento e heterogeneidade revelam ainda o fracasso de inúmeras tentativas do governo brasileiro em colocar em prática ideias originadas em contextos estrangeiros, fundamentados em cultura e em costumes particulares.

Dessa maneira, hábito ${ }^{1}$ é o principal elemento para compreender a noção Vebleniana de instituições. A forma como a moeda, o sistema bancário e as demais transações econômicas são socialmente construídos e "institucionalizados", por exemplo, representa a maneira como a sociedade reproduz os costumes coletivos, conduzindo-os para as próximas gerações. Para Hodgson (2005, p.652), "hábitos são mecanismos sociais, que envolvem a imitação de comportamento de uns indivíduos pelos outros; ou é resultado de um comportamento que é repetidamente constrangido por outros indivíduos". Hábitos de pensamento e de comportamento são distintos, segundo Hodgson (2006, p.141), isso significa que "um hábito adquirido não necessariamente é utilizado a todo o tempo. Um hábito ${ }^{2}$ é uma disposição de um indivíduo engajar um comportamento ou pensamento, mas ele precisa de um estímulo apropriado ou contexto para ser desenvolvido". Nesse sentido, o indivíduo pode não desenvolvê-lo no seu comportamento devido às limitações individuais ou às restrições de legitimidade social.

$\mathrm{Na}$ literatura recente, os hábitos são apontados como elementos centrais na composição de uma "nova" releitura da economia institucional vebleniana. Essa "releitura" fornece pistas analíticas para compreender as instituições de forma evolucionária. É disso que buscaremos tratar nos próximos itens, propondo uma nova interpretação do caráter vebleniano das instituições.

\footnotetext{
1 Uma discussão mais aprofundada de hábitos será apresentada na seção 3.4 deste artigo.

2 Outra noção relevante é a de instintos. De acordo com as ideias de Veblen, os indivíduos possuem racionalidade, que pode ser traduzida em diferentes objetivos, finalidades, consciências e preferências. Os instintos representam uma disposição comportamental herdada (HODGSON, 2004). É um elemento que funciona como uma orientação para a ação (VEBLEN, 1918), e "envolve consciência e adaptação para um fim almejado" (VEBLEN, 1918, p.4). Apesar da importância dos instintos no processo de formação de hábitos e nas possibilidades de transformações de interpretações e atitudes humanas, Veblen não deixa claro o sentido da herança do instinto.
} 


\section{ELEMENTOS PARA UMA RECOMPOSIÇÃo ANALÍtICA VEBLENIANA... E EVOLUCIONÁRIA}

Pelo exposto no item anterior, as instituições adquirem complexidade uma vez que estão condicionadas ao comportamento e à ação humana, que são heterogêneos. O legado de Veblen em torno dessa ideia é seguido, principalmente, por Geoffrey Hodgson, o qual argumenta que as instituições devem ser compreendidas em torno do conceito denominado "reconstitutive downward causation", que, recentemente, foi substituído por "effects". Nesse sentido, a análise institucional vebleniana parte da interação, onde instituições e indivíduos constituem o que chamamos de um "nexo micro-macro". Esses aspectos serão apresentados na sequência, buscando estabelecer uma nova ontologia evolucionária, como se procurará explicitar.

\subsection{Reconstitutive downward effects, cumulatividade e instituições}

Veblen, em "A Teoria da Classe Ociosa" (1899), argumenta que o papel dos indivíduos na constituição do ambiente institucional tem um duplo caráter. Ele tanto influencia, por meio de seus hábitos, crenças, padrões de comportamento e estratégias de ação, como é influenciado, por meio da cultura, das rotinas estabelecidas e dos padrões de emulação. Ou seja, os indivíduos influenciam e são influenciados pelas instituições. A esse processo Hodgson (2005, 2011) designou reconstitutive downward causation (ou effects). Tal proposição é derivada da "velha" ou Original Institutional Economics de Thorstein Veblen (1857 - 1929), onde interações culminariam no que ele designou da "causação cumulativa". Tal processo cumulativo era alimentado pelas mutações ao longo da progressão (ou evolução) do processo de crescimento e consolidação institucional. Em tal formação estava implícito que o "velho" ou antigo arcabouço institucional para o desenvolvimento econômico, tecnológico e social - que os neo-schumpeterianos vieram, nos últimos anos, a designar de paradigma tecno-econômico-, desdobravase em novas trajetórias, que brotavam pelas sucessivas mutações, trazendo "novidades sistêmicas", acompanhada de novas instituições, que substituíam, de forma irreversível, o "velho" paradigma pelo "novo".

O processo adaptativo: ... according to Veblen (1899, p. 190), the adaptive process works through both 'a selection between stable types of temperament and character' and 'an adaptation of men's habit of thought to changing circumstances' (Hodgson, 2007). Ou seja, a interação dos indivíduos com as instituições, através de seus hábitos de pensamento, conduz, por meio das próprias instituições, ao desenvolvimento da sociedade.

Sob a ótica vebleniana, a evolução das instituições não implica que elas sejam explicadas em termos de suas eficiências relativas em organizar a vida econômica dos homens. Em primeiro lugar, porque as instituições se adaptam a partir de circunstâncias passadas, o que, necessariamente, implica em não estarem em perfeito acordo com as demandas que surgem continuamente. Como salientou Veblen (1899, p. 191): "when a step in the development has been taken, this step itself constitutes a change of situation which requires a new adaptation; it becomes the 
point of departure for a new step in the adjustment and so on interminably". Em segundo lugar, a evolução das instituições não pressupõe a sua explicação em termos de eficiência relativa porque a mudança nos hábitos de vida e de formas de pensamento é algo que se processa de forma lenta e complexa, sendo difícil a sua caracterização instantânea. Em terceiro lugar, enquanto as classes inferiores têm um grande interesse na transformação da sociedade, elas, ao mesmo tempo, carecem de tempo e de energia para promover tais mudanças. No mais das vezes, tais classes estão subordinadas à hegemonia cultural imposta pelas classes privilegiadas. Por conta disso, e devido ao "prescriptive example of conspicuous waste and conservatism" (ibid., p. 205) das classes ricas, as classes inferiores gastam uma grande quantidade de energia buscando imitá-las, ao invés de tentar transformar os hábitos predominantes e criar uma identidade efetivamente autônoma.

Por fim, mudanças "eficientes" da sociedade são difíceis de ocorrer devido ao que se denomina "complementaridades institucionais", que caracterizam o sistema econômico. Tais complementaridades são os códigos de propriedades, convenções e costumes em voga em determinada época e entre algumas pessoas que constituem as características de um todo orgânico, de maneira tal que qualquer mudança apreciável em um ponto do esquema envolve mudanças ou reajustamentos em outros pontos também, se não uma reorganização geral.

\subsection{A relação indivíduo-instituição}

A relação entre indivíduos e estrutura constitui-se em um dos problemas centrais nas ciências sociais. Este é um ponto de partida vebleniano e institucionalista que é precioso para a inter-relação com as abordagens que propõem tal vinculação. Apesar de parecer óbvio, grande parte do mainstream não pensa assim. Bastariam bons fundamentos macro e microeconômicos que estariam asseguradas a "boa performance", sem a adequada mediação estrutural, que, aliás, é desnecessária, por fugir dos bons fundamentos. Fundamentos não explicam estrutura, mas acomodam-na.

Os recentes desenvolvimentos na teoria social sobre a relação entre estrutura e agência humana adicionam o conceito de hábito, que aglutina ambos. Tal noção origina-se do pragmatismo e da economia institucional vebleniana. Os processos de "habituação" proporcionam o mecanismo de reconstitutive downward causation, em que as circunstâncias institucionais afetam as preferências individuais, de forma interativa e em retroalimentação. E é essa interação mútua que se relaciona com a abordagem evolucionária.

Esse é o sentido em que estrutura social e indivíduos sempre interagem, tornando, de um lado, as instituições resultantes dos hábitos, crenças, padrões de comportamento dos indivíduos e que, ao mesmo tempo, repercutem, reforçando, ou não, tais convenções coletivas. A ação individual materializa-se da base para o topo e a ação coletiva faz o caminho contrário por intermédio das instituições. Essa é a razão que levou o pensamento institucionalista, herdeiro da tradição de Veblen, 
a questionar tanto $\mathrm{o}$ individualismo ${ }^{4}$ metodológico quanto $\mathrm{o}$ coletivismo metodológico. Nem um nem outro são suficientes, mas a ação conjunta e simultânea de indivíduos e estruturas na conformação social.

E tais aspectos metodológicos têm uma importância fundamental para a análise teórica e empírica em economia, como se verá neste texto. O que procuramos analisar é que o problema indivíduo-estrutura tem, atualmente, duas implicações que devem ser enfatizadas. A primeira é a crítica ao que é designado de "individualismo metodológico", que envolve noções como o reducionismo. Tal noção negligencia as estruturas, instituições e organizações, que deveriam ser também analisadas em termos de indivíduos e suas partes. A segunda implicação é a argumentação segundo a qual a concepção de "agente humano" deve ser profundamente reformulada, em contraste com a concepção dominante no mainstream econômico e social.

A economia institucional tem um sistema macroeconômico centrado no exame dos padrões e regularidades do comportamento humano, buscando identificar alguns conceitos como o da imitação, inércia, lock-in e "causação cumulativa" (Hodgson, 1998, p. 171). As regularidades ou estabilidades no nível sistêmico ocorrem, não apesar de, mas devido às variações no nível micro. Nesse sentido, em sintonia com os neo-schumpetianos, como Dosi e Nelson, as mutações ou estabelecimento de novas regularidades do processo de destruição-criadora eclodem do nível micro e tomam forma "agregada" no plano macro.

Tal perspectiva é bastante diferente da construção microeconômica a partir de "sólidos microfundamentos", dos quais derivariam as regularidades macroeconômicas, como o faz a abordagem mainstream. As regularidades do institucionalismo manifestam-se no nível sistêmico (através do mecanismo de reconstitutive downward causation), e são reforçadas por feedbacks positivos, que reagem novamente (reinforcement) sobre o nível macroeconômico, estabelecendo assim uma permanente interação micro-macro. Observe-se que nenhum dos elementos constitutivos dessa interação é percebido como "dado": há permanentemente a possibilidade de surgirem "novidades" ou inovações, oriundas do comportamento dos próprios agentes e da evolução das instituições.

Os hábitos dos indivíduos tanto fortalecem quanto são fortalecidos pelas instituições. Esse círculo de engajamento mútuo caracteriza as instituições como uma estrutura cognitiva de interpretação das informações e dos dados, que reforçam, por sua vez, de maneira cumulativa, os hábitos e as rotinas. Nessa dinâmica, o processo de "autonomia" da macroeconomia e a operacionalidade dos agregados devem ser reavaliados: a forma "reducionista" de análise que vê a macroeconomia como necessariamente explicada em termos microeconômicos (qual seja, o da derivação do
4 Para Elster (1982, p.453, apud Hodgson, 2004, p.16), o individualismo metodológico pode ser definido pela "doutrina que defende que todo fenômeno social (sua estrutura e sua mudança) é, em princípio, explicável unicamente através de indivíduos - seus objetivos e crenças". Elster, J. Marxism, Functionalism and Game Theory. Theory and Society. no 11, pp. 453 482, 1982. 
comportamento do agregado explicado a partir do desagregado) perde sentido. As instituições quebram essa possibilidade e o reducionismo desaparece. O que se estabelece é um processo de "causação cumulativa", que define padrões de conduta e hábitos que se reforçam mutuamente. ${ }^{5}$ Dessa maneira, os institucionalistas centram-se nas características específicas de instituições ao invés de construir modelos gerais e a-históricos centrados nos agentes individuais. Estes se relacionam por meio de instituições, razão pela qual é impossível tê-los como exógenos, como faz a abordagem convencional. Porém, tal proposição não pode ser confundida com o coletivismo metodológico, no qual o comportamento do indivíduo é totalmente explicado em termos de ambiente institucional e cultural. O comportamento individual pode ser explicado pela ação coletiva, assim como a ação individual influencia na formação e transformação de hábitos que são compartilhados. Esse ponto será mais bem discutido na seção seguinte.

Tais proposições confrontam-se com o projeto dos microfundamentos do mainstream, que esbarra na impossibilidade de ser modelado em termos de indivíduos. De acordo com tais fundamentos, há dois níveis de análise: o micro e o macro. Mesmo que cada um preserve sua relativa autonomia teórica, ambos são, ao mesmo tempo, conectados por meio de vínculos conceituais e explicativos. A crítica ao mainstream não torna o institucionalismo necessariamente inapto à construção de modelos e de fazer previsões, mas o faz levando em conta a persistência dos hábitos, o lock-in e os mecanismos de self-reinforcement, que implicam em análises tanto quantitativas quanto qualitativas, cujos pontos serão mais bem discutidos nas próximas sessões. Ou seja, ao invés de centrar-se na interpretação dos modelos em si, a análise institucionalista busca um outro método, cujas mediações com os indivíduos, lock-in e self-reinforcement estabelecem um outra ontologia, centrada em novo nexo metodológico.

\subsection{Um novo nexo metodológico: dos hábitos às instituições}

A partir da rejeição do approach neoclássico, centrado na maximização da utilidade dos indivíduos, os "velhos" institucionalistas centram-se na "agência humana". Tal influência é derivada de duas correntes do início do século XX, da psicologia, de William James e William McDougall, e da filosofia pragmática, de Charles Sanders Peirce. Em todos eles há forte influência da biologia darwiniana, que passa a centrar-se crescentemente nas noções de hábito como base da ação humana e das crenças. Ao contrário do mainstream, que vê os hábitos como derivados do comportamento
5 Uma importante observação de Hodgson (1998) relativa à importância do velho institucionalismo é que a contribuição de Mitchell e seus colegas do

National Bureau for

Economic Research desempenhou, nos anos 20 e 30, papel decisivo na contabilidade nacional e no estudo dos agregados macroeconômicos, que passaram a assumir uma nova legitimidade empírica, teórica e ontológica. Sua incursão contra o reducionismo criou espaço para a revolução keynesiana, o que explica a afinidade até hoje existente entre institucionalismo e póskeynesianismo. 
racional e resultado de escolhas prévias, para os velhos institucionalistas há uma inversão dessa lógica: a escolha racional é que deve ser explicada em termos de hábitos. Ou seja, os hábitos se vinculam ao conhecimento e às crenças, contribuindo para sua consolidação e legitimação social. Em termos evolucionários, todas as ideias, crenças, preferências e modo de cálculos racionais são adaptações evolucionárias às circunstâncias, que se estabelecem pela consolidação de hábitos.

Walton Hamilton (1932, p. 84) forneceu uma importante definição de instituição conectando-a com a noção de hábitos. Para ele, instituição é " a way of thought or action of some prevalence and permanence, which is embedded in the habits of a group or the customs of a people." Tal definição caminha no mesmo sentido da clássica noção de Veblen (1919) para as instituições, qual seja: a de um conjunto de hábitos de pensamento comum à generalidade dos homens. Já a $\mathrm{NEl}$, em contraste, não inclui em sua definição a noção de hábitos, mas opta por uma definição mais restrita, em que aparece como "regularidades gerais do comportamento social" (Schotter 1981, p. 11) ou como "the rules of the game in society or ... the humanly devised constraints that shape human interaction" (North ${ }^{6}$ 1991, p. 3 apud Hodgson, 1998, p. 179).

Como menciona Hodgson (1998, p. 179), todas essas definições incorporam pontos em comum que podem ser agrupados nas seguintes características:

(i) todas as instituições envolvem interação com agentes, com retorno de informações; (ii) todas as instituições têm um número de concepções características comuns e de rotinas; (iii) instituições sustentam e são sustentadas por concepções compartilhadas e por expectativas; (iv) embora não sejam imutáveis, nem imortais, as instituições têm qualidades relativamente duráveis, auto-alimentadas (self-reinforcing) e persistentes; (v) instituições incorporam valores e processos de avaliação normativa. Em particular, as instituições realimentam sua própria legitimação moral: razão pela qual sua persistência é frequentemente, certa ou erradamente, vista como moralmente justa.

Apesar das divergências e semelhanças, o que distingue o velho do novo institucionalismo é o conceito de hábito como elemento central. Para os "velhos", os hábitos são vistos como cruciais à formação e manutenção das instituições, uma vez que fazem parte da estrutura cognitiva dos indivíduos. Essa, por sua vez, é que permite o aprendizado e o conhecimento dos mesmos, dentro da respectiva estrutura institucional. Portanto, a habilidade de aprendizado encontra-se enraizada nos hábitos que formam as instituições. Em uma aproximação com a linguagem neo-schumpeteriana, segundo Hodgson (1998, p.180):
6 NORTH, D.C. Institutions. The Journal of Economic Perspectives, Sidney, $v$. 5, n. 1, p. 97-112, 1991. Disponível em:<http://www.jstor.or g/stable/1942704> Acesso em: 30 mar. 2009. 
[...]"habits and routines thus preserve knowledge, particularly tacit knowledge in relation to skills, and institutions act through time as their transmission belt. Institutions are regarded as imposing form and social coherence upon human activity partly through the continuing production and reproduction of habits of thought and action. This involves the creation and promulgation of conceptual schemata and learned signs and meanings. Institutions are seen as a crucial part of the cognitive processes through which sense-data are perceived and made meaningful by agents".

O velho institucionalismo vê os hábitos de comportamento como interrelacionados às estruturas institucionais, onde ambos se reforçam mutuamente. A escolha das instituições como unidades de análise não significa que o papel dos indivíduos é periférico e subordinado às instituições. A dualidade entre ambos é necessária: tanto indivíduos quanto instituições são mutuamente constitutivos um do outro. Instituições moldam e são moldadas pela ação humana. A esse conceito interativo Hodgson (2006) designou Reconstitutive Downward Causation, ou Effects (HODGSON, 2011).

Entendemos que uma (re)leitura sobre a forma ou padrões de desenvolvimento nos vários ambientes econômicos regionais, não pode, em nossa visão, prescindir das contribuições institucionalistas aqui esboçadas. Em especial, a incorporação da relação indivíduo-instituição é pertinente para uma nova interpretação analítica, capaz de fazer frente aos novos desafios interpretativos dos tempos modernos. Tal interpretação analítica será sintetizada na próxima seção.

\section{OS INDIVÍDUOS E AS INSTITUIÇÕES: A INTERPRETAÇÃO RELACIONAL E COLETIVA}

Com base no exposto na seção anterior, o pensamento Vebleniano sobre instituições situa-se dentro de uma proposta teórico-analítica relacional, resultante de um processo de interdependência do indivíduo para a instituição e vice-versa. Tal processo, denominado por Hodgson (2004) de reconstitutive downward causation ou effects, é realimentado pelas propriedades emergentes, que conformam, cristalizam e/ou modificam a trajetória institucional. No entanto, devido ao seu caráter processual e evolucionário, as instituições não podem ser restritas às condições de mudanças de hábitos temporários sem que haja relação com o pensamento (HODGSON, 2006). Esse é o caso das pessoas que mudam as suas ações tendo em vista evitar a ocorrência de multas no trânsito, comportando-se de forma diferente quando estão sendo fiscalizadas (HODGSON, 2006). Tal situação coloca em evidência a análise institucional vebleniana, pois ao considerá-la como dependente do pensamento e da ação, é possível afirmar que nem todo comportamento coletivo resultará em mudanças institucionais.

Por outro lado, no caso de algumas políticas governamentais, tais como as políticas públicas, as mudanças podem ser verificadas apenas na interpretação e nas ideias das pessoas, as quais, apesar da legitimação, podem possuir limitações para acessá-las. Nessas situações, as transformações atingem somente o nível do pensamento, já que as pessoas encontram dificuldades em reproduzir e/ou compartilhar esse comportamento. Esses são os casos, por exemplo, de inúmeras políticas que definem critérios econômicos e sociais para o acesso. Com base nas 
ideias veblenianas, entender uma política, regra ou contrato é apenas uma parte do processo de mudança institucional. Para que tal processo ocorra, é preciso que as mudanças estejam conectadas ao pensamento e ao comportamento, que podem ser transformados ao mesmo tempo ou em períodos diferentes.

As instituições são variáveis de acordo com os agentes econômicos, o que significa que nem todos os indivíduos compartilham o mesmo conjunto de ideias, interpretações e comportamentos. Enquanto alguns agentes possuem ideias individuais mais próximas daquilo que representam "as interpretações coletivas", outros podem possuir apenas uma parte dessas ideias. Portanto, o indivíduo "modelo" preconizado pela economia neoclássica não encontra espaço nas ideias veblenianas, pois os indivíduos possuem, por natureza, comportamentos heterogêneos, assim como recebem de forma diferente os estímulos para realizar mudanças nas suas ações.

Dependendo do contexto empírico da pesquisa, a análise pode ser baseada nos seguintes recortes: (i) a partir dos hábitos que um grupo de indivíduos possui para uma determinada atividade e/ou setor específico; (ii) a partir de um período de transformações na sociedade, tal como é a construção e operacionalização de novos programas, ações e políticas governamentais. Em ambos os exemplos, o questionamento parte da forma como as pessoas interpretam e adotam determinadas práticas e condutas nas suas vidas e nas suas atividades, as quais podem influenciar na vida em coletividade.

Do ponto de vista analítico-metodológico, as lentes são minimizadas e maximizadas: das informações do todo para as partes e das partes específicas para o todo, de forma relacional e cumulativa. Essa é a forma de compreender como os indivíduos estão relacionados uns com os outros da mesma forma que também é possível compreender em que medida as transformações originadas no ambiente coletivo influenciam em mudanças nos ambientes individuais (de cada indivíduo) e vice-versa.

No decorrer da análise institucional, surgirão elementos resultantes dos processos de interações, que poderão ser captados a partir da combinação de uma série de depoimentos dos entrevistados da pesquisa. Assim, o conjunto de respostas dos indivíduos analisados deve ser cruzado, tendo em vista encontrar ideias, interpretações e condutas comuns. Na tentativa de construir caminhos teóricos e esquemas analíticos, os pressupostos da economia institucional vebleniana poderão ser complementados, desde que haja fundamentação coerente e condizente a essa ontologia evolucionária. Para tanto, a próxima seção terá como finalidade apresentar algumas dessas possibilidades.

\subsection{Os múltiplos níveis das instituições}

A complexidade da noção de instituições de Veblen exige a busca de outras abordagens complementares para a operacionalização dos problemas de pesquisas. Uma das principais questões refere-se à necessidade de fazer um recorte da diversidade de instituições que estão compondo as relações e as atividades humanas. Do ponto de vista analítico, é inviável abranger a multiplicidade, mesmo quando o recorte corresponde a uma atividade ou a um setor específico. Outra questão é considerar qualquer conduta ou interpretação social como sinônimo de 
instituição. Como já descrito nas seções anteriores, há pelo menos três elementos que conceituam instituições: primeiro, elas dependem da ação e do comportamento que são coletivos e interligados; segundo, são resultantes da história e da maneira pela qual os indivíduos projetam o futuro e, terceiro, são modificadas a partir de mecanismos coletivos de seleção, que "descartam" ações e comportamentos que não possuem mais sentido para a representação social.

Partindo desses pressupostos, alguns caminhos para complementação, oriundos de outras perspectivas e noções teóricas das ciências econômicas e sociais serão apresentados nesta seção. $\mathrm{O}$ primeiro deles está relacionado à ideia das instituições em diferentes níveis, que é abordado pela Perspectiva Multinível7 - PMN. Sob essa perspectiva, considera-se instituição no plural (instituições), com diferenças normativas que ordenam e fundamentam comportamentos coletivos, podendo ser classificados em três níveis: micro, meso e macro. Assim, pode-se compreender instituições: (i) no nível de indivíduos e de grupos sociais (nível micro); (ii) no âmbito da nação, a partir do entendimento sobre regras, políticas, governo, formação de movimentos sociais (nível meso); e também (iii) no nível que envolvem o desenvolvimento e as transformações coletivas do âmbito da sociedade global (que representaria o nível macro).

Dentre as aplicabilidades possíveis, a análise das instituições em multiníveis apresenta potencial para compreender as mudanças e regras nos mercados agroalimentares. Sobre isso, destacam-se os atuais conflitos envolvendo as regras sanitárias e a produção artesanal de alimentos da agricultura familiar no Rio Grande do Sul. Do ponto de vista histórico, as instituições - representadas pelos hábitos de produção e de comercialização, tanto de produtores rurais quanto de consumidores - estiveram alicerçadas sob os atributos culturais, regidos por costumes locais. No entanto, a partir da década de 1950, o cenário da legislação brasileira passou a regulamentar a produção agroalimentar, estabelecendo critérios fundamentados exclusivamente nos parâmetros de qualidade técnico-científicos. Tais padrões, em sua maioria, divergiram da forma pela qual a produção e o consumo de alimentos artesanais estavam inicialmente constituídos, enraizados na cultura e na identidade local (AGNE, 2014).

Mesmo apesar de inúmeras mudanças - ocorridas especialmente a partir dos anos 2000 - o cenário atual ainda é caracterizado pela heterogeneidade institucional. Em algumas situações, ainda é possível descrever um contexto com dois polos opostos, muitas vezes sem perspectivas de interface institucional: de um lado, agricultores e suas organizações de apoio defendendo os seus modos de produção e de outro, órgãos públicos e secretarias responsáveis pela aplicabilidade das leis, os quais percebem o aparato legal como instrumento para garantir a segurança alimentar dos consumidores (AGNE, 2014). Assim, o que está em jogo são as
7 Tal abordagem surgiu a partir da necessidade de compreender o processo pelo qual as mudanças tecnológicas acontecem na sociedade, por meio de transições para diferentes paradigmas tecnológicos. Tais transições são

analisadas a partir de três níveis heurísticos: o nível micro (denominado

"nicho"), o nível meso (chamado "regime") e o nível macro (denominado "paisagem") (GEELS, 2002, 2004). Em estudos recentes, essa

abordagem tem sido utilizada nas investigações que envolvem a compreensão de mudanças tecnológicas na agricultura, enfatizando as

inovações e técnicas construídas a partir de relações sociais localizadas (MARQUES, 2009). 
distintas interpretações e visões de mundo em torno dos alimentos, dos seus modos de produção e consumo. Também está incluída uma diversidade de pensamentos em torno da definição de qualidade, que não necessariamente corresponde aos parâmetros técnicos e/ou científicos.

Essas situações exemplificam o aspecto diverso das instituições, cujos hábitos coletivos podem ser tanto traduzidos em leis formais como também podem estar representados nas ações cotidianas das famílias e de seus mercados consumidores. Ademais, a heterogeneidade das instituições inclui a própria interface de interpretações, podendo dar origem a novos comportamentos.

A produção orgânica de alimentos é outro exemplo, a qual nem sempre é orientada sob o aparato da legislação. Além da ausência da certificação, não é raro encontrar famílias que desenvolvem equipamentos e materiais baseados nos seus próprios conhecimentos em torno da produção industrial. Quando tais inovações são legitimadas socialmente, elas podem adquirir um "status" institucional além do nível micro, podendo influenciar na formalização de legislações nos níveis meso e macro (MARQUES, 2009).

Dessa forma, no nível micro, as instituições representam formas de identidade social e coletiva, que podem evoluir para o desenvolvimento de mudanças mais amplas. As instituições são, portanto, passíveis de transformação, na medida em que possam provocar "mudanças graduais, pressionar o sistema, por meio de conflitos e crises, transformando atitudes e ações, que são cumulativamente reforçadas" (CONCEIÇÃO, 2002, p.122). No entanto, as mudanças dependerão da capacidade dos atores em construir relações em redes, estabelecendo contatos e compartilhando interpretações em distintos espaços públicos (AGNE, 2014).

As redes, portanto, constituem caminhos para as mudanças institucionais. Nesse sentido, a noção de instituições de Veblen associa-se às contribuições da Nova Sociologia Econômica, especialmente sobre a definição de redes sociais de Mark Granovetter $(1973,1985)$. As redes sociais explicam as atividades econômicas, tais como as oportunidades de mercados e de trabalho. Tanto Veblen quanto Granovetter focam o comportamento coletivo dos indivíduos, que estão constantemente em interação, influenciando uns aos outros por meio de suas trajetórias de vida. Ambos percebem os indivíduos e a sociedade como elementos complementares: Granovetter (1973) ressalta que essa união pode ser compreendida por meio da noção de laços fracos, e Veblen (1987) afirma que os hábitos podem relacionar analiticamente indivíduo e instituição.

A análise das mudanças institucionais pode ser facilitada pela noção de redes sociais, especialmente se o foco for compreender os caminhos que os indivíduos utilizam para construir novas interpretações coletivas. Como descreve Fuhse (2009, p.62), "as redes não são uma mera soma de relações sociais, e sim uma estrutura de laços inter-relacionados". Para Long (2001, p.89, tradução nossa), as "redes são elementos chaves para as pessoas obterem informações, formarem opiniões, mobilizarem recursos ou para criarem espaços sociais e políticos".

Ambas as noções (multinível e redes sociais) trazem consigo a importância da análise sobre os contextos coletivos na transformação de comportamentos. A questão que está implícita nessas abordagens é a investigação sobre os elementos que conduzem os atores sociais em modificar as formas de perceber, decidir e agir 
nas atividades das quais participam. Essas mudanças podem surgir em diferentes níveis, em diversos setores e cujos resultados podem ser bem diferentes daqueles imaginados ou planejados a priori. Essas circunstâncias descrevem os aspectos evolucionários nos quais a teoria Vebleniana está alicerçada: os indivíduos herdam hábitos de forma cultural e histórica; os selecionam através das suas decisões coletivas e os transformam de acordo com suas "novas" atitudes e suas "novas" ações. A visão evolucionária corresponde à ideia de que o "novo" não é rompido com as circunstâncias do passado, ele é reinventado a partir das experiências das pessoas, a partir dos elementos do presente e também das perspectivas que elas têm sobre o futuro.

Considerar que as instituições operam em diferentes níveis - cujas mudanças são influenciadas pelas dinâmicas interativas em redes - pode ser um dos caminhos para a operacionalização da abordagem vebleniana. $\mathrm{Na}$ atualidade, com a velocidade da transmissão das informações e facilidade em construir contatos sociais, as ações coletivas do nível micro podem chegar com maior rapidez nos níveis meso e macro institucional. Tais interações podem influenciar em novos regimentos que podem formatar comportamentos sociais, e, ainda, não podem ser unicamente sustentadas pelas relações face a face. Este é caso das atuais mobilizações políticas emergentes no contexto das redes sociais, que provocam novos hábitos de pensamento e comportamento coletivos.

Para uma agenda futura de pesquisas, os "institucionalistas veblenianos" enfrentarão alguns desafios de investigações, os quais envolvem realizar escolhas, sintetizar informações e dados sem perder a multiplicidade dos hábitos humanos envolvidos. Ademais, o caminho metodológico é uma rota que será construída ao longo da própria pesquisa, sem que haja, a priori, o estabelecimento de hipóteses "fechadas" e/ou premissas que possam antever e/ou reduzir os resultados que serão encontrados.

$\mathrm{Na}$ tentativa de apresentar alguns desafios de operacionalização e pincelar algumas ideias metodológicas, a próxima seção terá como finalidade apresentar algumas "ferramentas" para coleta e análise dos dados, que envolvem resgatar memórias e mapear objetivos sociais coletivos.

\subsection{Qualificando e quantificando as instituições: proposições teórico-analítico- metodológicas}

Uma das principais questões que preocupam os estudiosos da teoria institucional vebleniana é: como entender o pensamento e o comportamento dos indivíduos, considerando que ambos são tão complexos e difíceis de serem mensurados, avaliados e sintetizados? Sobre isso, Stanfield (1999) fornece algumas pistas: o método de pesquisa qualitativo apropriado para tratar de instituições deve ter elementos antropológicos, já que a generalização (análises realizadas) deve inferir sobre as atividades de grupos sociais (STANFIELD, 1999). No entanto, alguns métodos da antropologia e da sociologia podem ser complementados com ferramentas quantitativas, especialmente com o uso de escala Likert e estatística, tal como fizeram Agne (2014) e Viana (2011). Dependendo de qual atividade ou grupo social a pesquisa se destina, é necessário ainda que o pesquisador se concentre em compreender um contexto delimitado e coletivo. A análise difere do 
olhar do pesquisador sobre cada indivíduo, família ou grupo social. Pelo contrário, o "objeto de pesquisa" - o ator entrevistado - deve ser compreendido através da sua inserção em um "cenário coletivo", que é traduzido pelo conjunto de atores sociais, os quais interagem com o (s) entrevistado (s). Porém, nem todo ator social ou interação social é considerada na análise, já que o pesquisador deve selecionar apenas as interações que ajudam a explicar os processos e as dinâmicas do contexto institucional investigado.

O ponto de partida pode envolver a compreensão sobre o conjunto de informações de um determinado grupo social, podendo ser aqueles que estão relacionados pela proximidade geográfica, ou seja, que residem no mesmo município ou região. Outra possibilidade é investigar sobre a formação de redes sociais, crenças e opiniões coletivas que são sustentadas pela troca de mensagens de forma virtual, por exemplo. Nessa situação, um dos exemplos mais marcantes refere-se às organizações e às mobilizações em torno da política que se iniciam a partir de redes sociais na internet, nos quais as pessoas identificam-se uma com as outras mediante o compartilhamento e divulgação de ideias e de atitudes coletivas.

Uma das principais limitações metodológicas do uso da abordagem institucional vebleniana refere-se ao tempo despendido para a coleta dos dados, já que tal perspectiva está ancorada com os fatos e acontecimentos históricos. Sobre isso, destaca-se a inclusão de estudos exploratórios aprofundados, a fim de obter indicativos precisos sobre a existência de inter-relações entre fatores e/ou elementos. No entanto, uma das principais dificuldades na realização de estudos exploratórios no que tange à análise institucional refere-se justamente à escolha de um elemento explicativo das instituições, especialmente quando não há indicativos claros e suficientes que suportem, a priori, a tomada dessa decisão.

Os elementos que irão compor o "esquema de análise coletivo" podem envolver não somente interpretações e condutas, mas também imagens, regras, normas, repertórios culturais, códigos de comportamentos, identidade e ações coletivas. Tais ideias são semelhantes às formas como Stanfield (1999, p.3) observa a análise das instituições, partindo de uma "especificação das atividades, regras e o entendimento sobre o comportamento humano, inserido em um contexto institucional". Essa forma de análise está relacionada também com a metodologia apresentada por Zilber (2002). O autor priorizou as informações empíricas relacionadas aos objetivos sociais comuns "common social accounts" e a diversidade de memórias coletivas "diverse collective memory"- cujas expressões sintetizam a escolha metodológica de análise que considerou o cruzamento entre o coletivo e "as referências dos atores em relação ao que eles estão fazendo e o significado das suas ações".

Ao utilizar a abordagem vebleniana, os pesquisadores devem ter, como um dos pressupostos, a coleta de informações que permitam entender tanto pensamento quanto comportamento. Tais elementos não são facilmente entendidos e explicados a partir de questões cujas respostas são compostas apenas de alternativas de escolha múltipla. A justificativa para essa divergência dá-se a partir da necessidade em entender as trajetórias de vida das pessoas, os principais acontecimentos durante essas trajetórias e as suas convergências e/ou divergências de opiniões e condutas coletivas. Ademais, as interpretações coletivas - e, portanto, institucionais - somente podem ser viabilizadas por meio da combinação de uma 
série de métodos: observações, entrevistas, participação em reuniões, eventos, organizações, conversas, diálogos, etc.

A percepção sobre os hábitos coletivos ficarão mais evidentes após o cruzamento de respostas/elementos que se repetem nos argumentos dos indivíduos e dos grupos sociais analisados. Stanfield (1999, p.3) resume em quatro passos a proposta de análise institucional vebleniana, que incluem:

(i) iniciar a análise com a notação dos fatos que serão explicados; (ii) investigar sobre as explicações para esses fatos; (iii) selecionar e oferecer alternativas que mais os explicam e (iv) articular valores, premissas e implicações para explicar pensamento e ação.

A trajetória dos entrevistados pode ser resgatada por meio de técnicas que permitem obter fatos e acontecimentos que marcaram a vida do indivíduo, como é o caso da história oral, que permite o registro de narrativas da experiência humana (FREITAS, 2006). Assim, os hábitos podem ser "captados" quando os entrevistados realçam fatos que marcaram seus cotidianos. Sobre isso, a técnica denominada "entrevista em profundidade", pode complementar tal análise, na medida em que permite captar a interpretação e a "visão de mundo" do indivíduo analisado (VEIGA; GONDIM, 2001). Permite focar, ainda, na forma como cada indivíduo interpreta os fatos, de forma particular e específica (CASSAB; RUSCHEINSKY, 2004). O registro dos dados, podendo ser realizado pela observação participante e pelo uso de diários de campo, podem ser outras propostas metodológicas, que facilitam a interpretação sobre as reuniões de pessoas e seus diálogos, os locais frequentados e as formas de identidade entre elas.

Dentre as possibilidades quantitativas, a escala Likert é uma das ferramentas mais utilizadas nas ciências sociais e econômicas, com o objetivo de entender o comportamento humano. Em estudos interdisciplinares na área da administração e da economia, tal instrumento tem sido utilizado para compreender perfis de consumidores e avaliar a aceitabilidade de produtos e marcas. Desenvolvida por Rensis Likert, em 1932, tal escala permite aos entrevistados assinalar uma resposta dentre cinco, sete ou nove pontos, e que apresentam alternativas desde altamente favorável até altamente desfavorável (ou vice-versa) (REA; PARKER, 2000, PEREIRA, 2004). Como uma das formas de complementá-la com informações qualitativas, pode-se criar questões para identificar justificativas para cada uma das respostas fornecidas na escala. As justificativas e os dados históricos podem auxiliar os pesquisadores na compreensão sobre o número da escala, especialmente sobre o significado que ele tem para o indivíduo entrevistado. Uma das limitações dessa técnica no emprego sobre a análise das instituições corresponde à característica estática da escala, já que a interpretação obtida refere-se a um determinado momento (de quando foi realizada a pesquisa). Para tanto, as possibilidades de combinação com outras questões históricas podem ter mais êxito, já que permite reconhecer se a avaliação (número fornecido) sofreu mudanças em algum período histórico. Caso a resposta seja positiva, os pesquisadores podem identificar o período e os fatores (causas) que condicionaram a ocorrência das mudanças nas interpretações coletivas.

Sintetizar os dados históricos relacionados às trajetórias de vida das pessoas é outro desafio. O uso da escala Likert, pode ser, ainda, complementada com a 
técnica denominada análise de conteúdo, que é caracterizada pela codificação da informação mediante a definição de categorias analíticas (REY, 2002). Nesse caso, um determinado fato, acontecimento, situação ou trajetória pode ser enfatizado, demonstrando as relações existentes entre eles e a importância dos mesmos para explicar a transformação das instituições.

Portanto, identificar os elementos que traduzem a forma como os atores sociais interpretam e conduzem as suas atividades é um desafio para uma futura agenda de pesquisas. Tais elementos nem sempre estão nítidos nas frases geradas pelos entrevistados, pois, em muitas situações, eles são gerados a partir da inferência, do cruzamento entre as informações empíricas, as noções e os referenciais teóricos utilizados no trabalho. No que se refere à operacionalização da noção de instituição como objeto empírico, o aporte da Economia Institucional Vebleniana funciona como um guia. A complementaridade vai sendo construída por meio de combinações e cruzamentos quali-quantitativos, adequados aos diferentes objetos e contextos da pesquisa.

\section{CONSIDERAÇÕES FINAIS}

O legado deixado pela relevância e profundidade do pensamento institucional, evolucionário e visionário de Veblen traz novos insights à teoria econômica contemporânea, que dificilmente poderão ser negligenciados. Buscouse, neste texto, estabelecer alguns pontos relevantes desse legado que tem nos aportes evolucionários importantes interlocutores, com vistas à construção de uma nova ontologia sobre a dinâmica e a natureza do processo de desenvolvimento e mudança institucional.

Dos conceitos retratados, os hábitos constituem elementos explicativos da relação indivíduo-instituições. Observadas de forma interacional, as instituições sustentam a emergência de atitudes, percepções e visões coletivas, as quais podem vir a constituir e/ou divergir aos padrões de comportamento já formalizados e constituídos socialmente. A sociedade, quando coloca em xeque tais padrões estabelecidos, seja na esfera da política, do governo, dos mercados e/ou do consumo, pode provocar a emergência de novas identidades, justificadas por formas inovadoras de pensar e de viver.

No entanto, nas ciências sociais e econômicas, o entendimento e o uso da abordagem institucional vebleniana ainda está em fase de construção e consolidação. Os obstáculos estão relacionados com as dificuldades de estabelecer diálogos entre conceitos, noções e métodos, oriundos de diferentes áreas do conhecimento. Embora situado no escopo da economia institucional, o legado de Veblen é abrangente e interdisciplinar, o que possibilita analisar que as problemáticas no âmbito do desenvolvimento são caracterizadas pela natureza plural, evolucionária e multifacetada das instituições.

\section{REFERÊNCIAS}

AGNE, C.L. Mudanças Institucionais na agricultura familiar: as políticas locais e as políticas públicas nas trajetórias das famílias nas atividades de processamento de alimentos no Rio Grande do Sul. 2014. 259f. Tese (Doutorado em Desenvolvimento 
Rural) - Programa de Pós-Graduação em Desenvolvimento Rural, Universidade Federal do Rio Grande do Sul, Porto Alegre, 2014. Disponível em: <http://www.ufrgs.br/pgdr/dissertacoes_teses/arquivos/doutorado/PGDR_D_73_CH AIANE_AGNE.pdf>Acesso em 2 jul. 2014.

CASSAB, L.A; RUSCHEINSKY, A. Indivíduo e ambiente: a metodologia de pesquisa da história oral. Biblos, Rio Grande, n. 16, p.7-24, 2004. Disponível em: <http://www.seer.furg.br/ojs/index.php/biblos/article/viewFile/125/115> Acesso em: 16 jun. 2011.

COASE, R. The nature of the firm. Economica, London, v.4, n.16, p.386-405, 1937. Disponível em: <http://links.jstor.org/sici?sici=0013-

427\%28193711\%292\%3A4\%3A16\%3C386\%3ATNOTF\%3E2.0.CO\%3B2-B>. Acesso em: 12 set. 2013.

CONCEIÇÃO, O. A. C. O conceito de instituição nas modernas abordagens institucionalistas. Revista Economia Contemporânea, Rio de Janeiro, v.6, n.2, p.119146, jul./dez. 2002.

FREITAS, S. M. História Oral: possibilidades e procedimentos. 2 ed. São Paulo: Associação Editorial Humanitas, 2006.

FUHSE, J. A. The meaning Structure of social Networks. Sociological Theory, Washington, v.27, n.1, p.51-73, 2009.

GEELS, F.W. Technological transition as evolucionary reconfiguration processes: a multi-level perspective and a case-study. Research Policy, Amsterdam, n. 31, p. 12571274, 2002.

. From sectoral systems of innovation to socio-technical systems: insights about dynamics and change from sociology and institutional theory. Research Policy, Amsterdam, n. 33, p. 897-920, 2004.

GRISA, C. Políticas públicas para a agricultura familiar no Brasil: produção e institucionalização das ideias. 2012. 280 f. Tese (Doutorado em Ciências Sociais) Programa de Pós-Graduação de Ciências Sociais em Desenvolvimento, Agricultura e Sociedade. Universidade Federal do Rio de Janeiro, Rio de Janeiro, 2012. Disponível em: <http://r1.ufrrj.br/cpda/wp-content/uploads/2012/07/Tese-Catia-Grisa.pdf>. Acesso em: 20 abr.2013.

GRANOVETTER, M. S. La fuerza de los vínculos débiles. American Journal of Sociology, Chicago,v. 78, n. 6. p. 1360-1380, 1973. Disponível em: $<$ http://www.redcimas.org/archivos/analisis_de_redes/la_fuerza_de_los_vinculos_d ebiles.pdf> Acesso em: 3 set. 2008.. Economic action and social structure: the problem of embeddedness. American Journal of Sociology, Chicago, v. 91, n. 3, p. 481-510, 1985. Disponível em: <http://www.journals.uchicago.edu/AJS/> Acesso em: 18 jun. 2008. 
HAMILTON, W. H. Institution. Enciclopédia de ciências sociais. Eds.: EDWIN R. A. S; ALVIN J. New York: Macmillan. Vol. 8. pp. 84-89, 1932.

HODGSON, M. G. From micro to macro: the concept of emergence and the role of institutions. In: INTERNATIONAL SEMINAR INSTITUTIONS AND ECONOMIC DEVELOPMENT: TOWARDS A COMPARATIVE PERSPECTIVE ON STATE REFORM, 1., 1997, Rio de Janeiro. Anais... Rio de Janeiro, 1997. p.12-14. 1 CD-ROM.

.The approach of institutional economics. Journal of economic literature. Vol. 36, N. 1, March, p.166-192, 1998.

. The evolution of institutional economics: agency, structure and darwinism in american institutionalism. New York: Routledge, 2004.

. Generalizing darwinism to social evolution: some early attempts. Journal of Economic Issues, Salisbery, vol. 34, n.4, p.899-914, Dec. 2005.

. What are institutions? Journal of Economic Issues, Salisbury, v. 40, n. 1, p.125, Mar. 2006.

.Downward causation: some second thoughts. Disponível em: <http://www.geoffrey-hodgson.info/downward-causation.htm> Acesso em 21 jul. 2014 .

LONG, N. Development Sociology: actor perspectives. New York: Routledge, 2001.

MARQUES, F.C. Velhos conhecimentos, novos desenvolvimentos: transições no regime sociotécnico da agricultura: a produção de novidades entre agricultores produtores de plantas medicinais no Sul do Brasil. 2009. 220 f.Tese (Doutorado em Desenvolvimento Rural) - Programa de Pós-Graduação em Desenvolvimento Rural, Universidade Federal do Rio Grande do Sul, Porto Alegre, 2009.

NELSON, R.R., WINTER, S. An evolutionary theory of economic change. United States: Harvard College, 1982.

PEREIRA, J.C.R. Análise de dados qualitativos: estratégias metodológicas para as ciências da Saúde, humanas e sociais. 3. ed. São Paulo: Editora da Universidade de São Paulo, 2004.

REA, L.M.; PARKER, R. A. Metodologia da pesquisa: do planejamento à execução. São Paulo: Guazelli, 2000.

REY, F.L.G. Pesquisa qualitativa em psicologia: caminhos e desafios. São Paulo: Pioneira, 2002. 
SCHOTTER, A. The economic theory of social institutions. Cambridge and New York: Cambridge U. Press, 1981.

STANFIELD, J.R. The scope, method and significance of original institutional economics. Journal of Economic Issues, Salisbury, v.33, n.3, p.230-255, 1999.

VEBLEN, T. Why is economics not an evolutionary science? The Quarterly Journal of Economics, Cary, v. 12, n. 4, p. 373-397, 1898. Disponível em:

<http://www.jstor.org/stable/1882952>. Acesso em: 28 dez. 2010.

. A teoria da Classe Ociosa. São Paulo: Nova Cultural, 1987.

. The place of science in modern civilization and others essays. New York: B. W Huebsch, 1919.

.The instinct of workmanship and the state of the industrial arts. New York: B.W. HUEBSCH, 1918.

VEIGA, L.; GONDIM, S.M.G.; A utilização de métodos qualitativos na ciência política e no marketing político. Opinião Pública, Campinas, v. 7, n.1, p. 1-15, 2001. Disponível em: <http://www.scielo.br/pdf/op/v7n1/16930.pdf> Acesso em: 23 nov. 2011.

VIANA, J. G. Evolução da produção ovina no Rio Grande do Sul e Uruguai: análise comparada do impacto da crise da lã na configuração do setor. 2011. 180 f. Tese (Doutorado em Agronegócios) - Centro de Estudos e Pesquisas em Agronegócios, Programa de Pós- Graduação em Agronegócios, Universidade Federal do Rio Grande do Sul, Porto Alegre, 2011.

WILLIAMSON, O.E. The mechanisms of governance. New York: Oxford University Press, 1996.

ZILBER, T.B. Institutionalization as an interplay between actions, meanings and actors: the case of a rape crisis center in Israel. The Academy of Management Journal, Malden, v. 45, n.1, p.234 - 254, 2002. Disponível em:

<http://www.jstor.org/stable/3069294>. Acesso em: 28 maio 2013.

Chaiane Leal Agne. Graduada em Administração, Mestre e Doutora em Desenvolvimento Rural (Programa de Pós-graduação em Desenvolvimento Rural, UFRGS), Professora Adjunta em Desenvolvimento Rural da Universidade Estadual do Rio Grande do Sul (UERGS), Unidade Cachoeira do Sul, Campus Regional. chaianeagne@uergs.edu.br

Octavio Augusto Camargo Conceição. Graduado em Economia, Mestre em Economia Rural e Doutor em Economia. Professor Associado da Universidade Federal do Rio Grande do Sul (UFRGS). Departamento de Economia e Relações Internacionais e do Programa de Pós-Graduação em Economia. Pesquisador do CNPQ.octavio@ufrgs.br 